\title{
Successful treatment of anisometropic amblyopia and strabismus following intravitreal silicone oil
}

\author{
R R Goble, W A Franks, D Avery, A H Chignell
}

Silicone oil is used in the treatment of complex retinal detachments. Its refractive index $(1 \cdot 400$ $1.405)$ is higher than that of vitreous $(1.336)$ and can cause a refractive change to high hypermetropia in the phakic emmetropic eye. ${ }^{1}$ This degree of anisometropia can lead to the development of amblyopia in young children.

A 6-year-old boy developed a traumatic retinal detachment successfully treated by vitrectomy and intravitreal silicone oil. Postoperative anisometropic amblyopia and secondary esotropia developed. The amblyopia was successfully treated with hypermetropic spectacles and occlusion. This was followed by oil removal and strabismus surgery. Full stereopsis eventually recovered.

\section{Case report}

A 6-year-old boy was referred 1 month after blunt trauma to his left eye with an inferior retinal detachment and a post-equatorial break at 8 o'clock associated with preretinal membrane. The macula was uninvolved and there was no significant anterior segment damage. Since initial presentation, the left visual acuity had been $6 / 18$ due to vitreous haemorrhage. The patient had passed a school eye test the previous year. A pars plana vitrectomy was performed with peeling of the membrane surrounding the break. The retinal break was judged to be too posterior for scleral buckling so internal tamponade with silicone oil was used.

Ten days postoperatively, the unaided left visual acuity was counting fingers, which improved to $6 / 60$ with +8 dioptre sphere (cycloplegic refraction: $0.00 /+0.50 \times 90$ right and $+8 \cdot 00 /+0 \cdot 50 \times 170$ left). A left esotropia had also developed, measuring 35 prism dioptres at both $1 / 3 \mathrm{~m}$ and $6 \mathrm{~m}$ with the prism reflection test. Eye movements were full with normal saccades. The retina was attached, the fovea appeared normal on biomicroscopy, and there were no media opacities. A diagnosis of amblyopia with secondary esotropia was made. The amblyopia was treated for 1 hour each day with glasses and occlusion of the right eye.

The left visual acuity improved to $6 / 18$ with 1 month of treatment, and by 3 months was $6 / 6$. The left esotropia persisted. The silicone oil was removed. Forced duction testing and exploration of the horizontal recti were normal. A $5 \mathrm{~mm}$ medial rectus recession and a $7 \mathrm{~mm}$ lateral rectus resection were performed.

Two weeks after silicone oil removal, the left visual acuity was $6 / 6$ unaided $(+0.00 /+0.50 \times$ 170 left). A 10 prism dioptre esotropia at $1 / 3 \mathrm{~m}$ and $6 \mathrm{~m}$ persisted. The patient experienced diplopia and this was confirmed on orthoptic assessment with Bagolini glasses and Worth's four light test.

Six months postoperatively no manifest deviation was present and the TNO stereoacuity was 240 seconds of arc. At 1 year full binocular function had returned with a TNO stereoacuity of 60 seconds of arc and there was a prism fusion range of 20 dioptres base in and 45 dioptres base out.

More than 2 years after the injury the left visual acuity is $6 / 6$, the lens is clear, and the retina remains attached. There is no manifest squint and the patient retains full stereoscopic vision.

\section{Comment}

Retinal detachments in children are uncommon and are often traumatic in origin. If there is associated anterior segment damage and/or retinal detachment involving the macula then the visual prognosis may be poor. If the macula remains attached and there is no significant anterior segment injury then the visual results after surgery should be excellent.

Silicone oil is useful in the treatment of eyes with complex retinal detachments. ${ }^{2-4}$ The long term complications of silicone oil include glaucoma, cataract, silicone oil emulsification, and, in aphakic eyes, corneal opacification..$^{5-7}$ Provided the retina remains attached, silicone oil removal may prevent such problems arising. ${ }^{8-10}$

Children up to 8 years of age may develop amblyopia." The reduction in visual acuity to $6 / 18$ at presentation and for 1 month before detachment surgery was caused by the vitreous haemorrhage from the original injury. However, following intravitreal silicone oil injection, the uncorrected visual acuity dropped to counting fingers and even with the full refractive correction the acuity was only $6 / 60$. It was evident that in the absence of any structural abnormality the patient had developed silicone oil induced anisometropic amblyopia.

The esotropia developed within the first 10 days after surgery and was secondary to the anisometropic amblyopia. Following a period of loss of binocularity, a well controlled phoria may decompensate. This is a possible mechanism in this case. The 'blind spot syndrome', in which the diplopic image falls on the optic disc of the deviating eye, may be responsible for the large angle ( 35 prism dioptres) of squint in this case as well as the initial absence of diplopia. ${ }^{12}$ In some trauma cases, fibrosis of the extraocular muscles can produce strabismus. In this case the rapidity of onset, full movements, and normal muscle inspection all failed to support this aetiology. Detachment surgery itself may produce 
strabismus. The factors which predispose to this include the placement of scleral explants, scleral dissection beneath rectus muscles, and conjunctival scarring, none of which was a factor in this case. ${ }^{13}$

Loss of stereopsis occurred during the time that silicone oil remained within the eye, as the high degree of anisometropia produced insuperable aniseikonia. After the oil was removed, a small esotropia persisted for a few weeks until binocular single vision and eventually full stereopsis recovered. Unfortunately this recovery may not always occur following transient visual impairment in children, even in those known previously to have had normal binocular single vision. ${ }^{14}$

This case illustrates the importance of testing for silicone oil induced anisometropia in young children. It demonstrates that occlusion combined with the use of hypermetropic spectacles can prevent and treat the associated amblyopia which may compromise the results of otherwise successful detachment surgery. Removal of silicone oil should be undertaken as soon as possible to minimise the risk of developing this as well as its other long term complications.
1 Lean JS. Use of silicone oil as an additional technique in vitreoretinal surgery. In: Ryan SJ, ed Retina. Glaser BM, vitreoretinal surgery. In: Ryan SJ, ed. Retina. Glaser BM, Michels RG.

2 Cibis PA, Becker B, Okun E, Canaan S. The use of liquid silicone in retinal detachment surgery. Arch Ophthalmol 1962; 68: 590-9.

3 Scott JD. The treatment of massive vitreous retraction. Trans Ophthalmol Soc UK 1975; 95: 429-32.

4 Lean JS, Leaver PK, Cooling RJ, McLeod D. Management of complex retinal detachments by vitrectomy and fluid/ silicone oil exchange. Trans Ophthalmol Soc UK 1985; 102: 203-5.

5 McCuen B, de Juan E, Landers MB, Machemer R. Silicone oil in vitreoretinal surgery. 2: Results and complications. Retina 1985; 5: 198-205.

6 Leaver PK, Garner A, Grey RHB, Hitchings RA. Effects of intraocular silicone. Trans Ophthalmol Soc UK 1987; 97: 633.

7 Leaver PK, Grey RHB, Garner A. Silicone oil in the treatment of massive preretinal retraction. Late complications in 93 eyes. Br $\mathcal{F}$ Ophthalmol 1979; 63: 361-7.

8 Casswell AG, Gregor ZJ. Silicone oil removal: 1 The effects on the complications of silicone oil. Br F Ophthalmol 1987; 71: 893-7.

9 Franks WA, Leaver PK. Removal of silicone oil - rewards and penalties. Eye 1991; 5: 333-7.

10 Gonvers $M$. Temporary silicone oil tamponade in the management of retinal detachment with proliferative vitreoretinoment of retinal detachment with proliferative

11 Harwerth RS, Smith EL, Duncan GC, Crawford MLJ, von Harwerth RS, Smith EL, Duncan GC, Crawford MLJ, von
Noorden GK. Multiple sensitive periods in the development Noorden GK. Multiple sensitive periods in the developm
of the primate visual system. Science 1986; 232: 235-8.

12 Swan KC. The blind spot syndrome. Arch Ophthalmol 1948; 40: 371-88.

13 Munoz M, Rosenbaum AL. Long-term strabismus complications following retinal detachment surgery. $\mathcal{f}$ Pediat Ophthalmol Strabismus 1987; 24: 309-14.

14 Pratt-Johnson JA, Tillson G. Intractable diplopia after vision restoration in unilateral cataract. Am $\mathcal{F}$ Ophthalmol 1989; 107: 23-6. 